\title{
Owen Bullock
}

\section{Semiotics and poetry - why the relational axes might yet increase our understanding of poetic practice}

\begin{abstract}
The paper will consider syntagmatic and paradigmatic relations in the poetry of Michele Leggott. The syntagm is a sequential lexical unit, including anything from a compound noun to a line or stanza; it is seen as occupying a horizontal axis, and concerned with the positioning of words. The paradigmatic is a vertical axis and concerns possible substitution of words; it has much to do with the choices a particular poet makes which suggest the 'other', with aspects of composition that are less logical and more intuitive. The paper also considers the implications of the binary oppositions of this discourse and what the relational axes might say about the use of space in a poem. I argue that the use of space in the layout of a poem is paradigmatic rather than syntagmatic and that the use of space sometimes constitutes an act of substitution for language. The paper moves towards a wider understanding of semiotics with reference to deconstruction and assemblage theory.

Keywords: semiotics, poetry, space
\end{abstract}

If, as Roman Jakobson claims, 'poetics may be regarded as an integral part of linguistics' (Jakobson 2000a: 31), then the student of poetics can well afford to embrace linguistic discourse and linguistic tools. Focussing on syntagmatic and paradigmatic relations, I will analyse the work of New Zealand poet Michele Leggott for ways in which these relations are utilised in poetry, and to inform the reading of that work. The concern over what the relational axes can tell us about the composition of poetry that can then be used in practice is central to this paper. A poet's work is dependent on an awareness of the possibilities of language to create effects. The ideas of syntagmatic and paradigmatic relations introduced by Saussure still have potential to further the understanding of such possibilities in poetry, and most importantly for the individual practitioner, how they might be used. I will consider how space can be conceptualised, what functions space has within the layout of poetry, and how it intersects with language and meaning. I will argue that, at times, the use of space is an act of substitution for language.

Culler cautions against the proliferation of interpretations of texts (Culler 1975: 258; Culler 1981: ix), reminding us to question whether they do in fact aid understanding. Notwithstanding the fact that any interpretation may constitute another (creative) cultural artefact, I would like to suggest ways in which ideas 
and images might be formed and arranged in the poems studied; to distinguish between techniques via binary oppositions; to show how one contemporary poet manipulates the relational axes and how the different parts of the poem relate to the whole, as well as to the codes established by the reading of contemporary poetry. Widespread acceptance of the arbitrary nature of the sign, posited by Saussure, means that semiotics itself - the study of the sign represents a challenge to the literal and the idea that we can represent the world as it is (Chandler 2007: 123). These techniques together with the limitations of meaning that a poem seems naturally to encounter and convey may be interesting to the general reader, but my primary hope is that this discussion be useful to the poet.

Both the community and individual user are bound to their language, which is inherited from previous generations; social institutions are similarly adapted (Saussure 2005: 71-72). This might be said to include the norms of literary genres such as poetry. The formalists understood the evolution of literature as disrupting existing conventions and generating new ones (Rivkin \& Ryan 2004a: 4). This basic assumption seems to have both endured and developed, such as the understanding that a text - as opposed to the 'work' - generates and subverts meaning at the same time (Johnson 2004: 341). Furthermore, Kristeva believes that poetry confronts order, the logic of language and even the idea of the State (Kristeva 1984: 80). At the same time, we have to acknowledge that we read in relation to other texts and the codes that they help establish for reading. Though a text has a degree of autonomy, it is possible to reflect on the systems and processes that give rise to it (Culler 1981: 12, 37). Before we encounter this confrontational artefact, I will outline the main terms from semiotics to be sued in this paper.

The syntagm is a sequential lexical unit of two or more parts, including anything from compound nouns, to a phrase and whole sentences (Saussure 2005: 121-122; Martin \& Ringham 2006: 96). Some of these come as 'readymade' and idiomatic expressions over which the user seems to have little choice (Saussure 2005: 122-123); referred to as 'fixed syntagms'. We each possess a storehouse of similarities and differences between words and ideas, which were termed associative relations by Saussure. Though the syntagmatic chain occurs in praesentia (in sequence), the associative occurs in absentia, as a group of memories. An associative group can include any number of elements, in any order, i.e. non-linear (Saussure 2005: 122). Jakobson's term for associative relations, the paradigmatic, is now more commonly used (Chandler 2007: 84), and is the one I will follow.

For illustration, let's look at a poem by Michele Leggott:

\section{THRILLS (HELPLESS) \\ it's always this}

a violin

violins

violins wheeling in starts it 
going up taking up

If you've got

leaving on your

mind

(Leggott 1991: 11)

The word 'it's' is already a syntagm, a contraction of two words. The phrase 'it's always' is another lexical unit, a syntagm, and so on. But when we get to a violin wheeling, there is something illogical going on, since violins do not wheel. This metaphor is a paradigmatic usage.

In the second stanza, a fracture occurs after the second line's 'taking up', breaking like a train of thought, as the poet switches to what is really on her mind. The isolation of the word 'mind' also forces one to consider the role the mind plays, in terms of switching references and trains of thought in general. Here, jazz is evoked - Georgia on my mind - and the musical code begun with violins is extended. I will return to this poem shortly.

The linearity of the syntagm may suggest its occupying a horizontal axis, and, by contrast, the paradigmatic a vertical one. Barthes affirms the close connection between the syntagm and speech, explaining, 'the spoken sentence is the very type of the syntagm' (Barthes 1968: 62); language may be seen as paradigmatic. The syntagmatic axis is concerned with form and the paradigmatic with content (Chandler 2007: 86); the syntagmatic with the positioning of words (Hawkes 1977: 26), and the paradigmatic with substitution; the syntagmatic with combination and the paradigmatic with selection, or contrasts (Chandler 2007: 83-84; Culler 1975: 13-14). What is more, combination may be seen as an external relation and selection as an internal one (Jakobson 1971: 44). Endless binary oppositions can be made of this model, but it is the syntagmatic axis which determines meaning to the greatest extent (Hawkes 1977: 26).

The relational axes have been used by scholars such as Easthope, Culler and Riffaterre to analyse poetry. However, explicit references to the syntagmatic chain are far more common. The paradigmatic is often discussed in terms of its component features, such as metaphor and irony, with 'association' and the act of 'substitution' also common terms. The use of space is rarely discussed in literary criticism and is more likely a topic of discussion in the materiality of artists' books. Nevertheless, the three thinkers mentioned above are models in various ways. The relative lack of ongoing discussion of the paradigmatic perhaps reflects the era of the poetry examined in their examples; considering more recent developments in poetry, via a New Zealand example, may show that an old tool still has some work in it. Discussion of New Zealand poetry is almost completely lacking in any discussion of semiotics (bar a mention), so that I feel that my topic may also appeal to readers interested in New Zealand poetry, as well as practitioners.

In poetry, the paradigmatic axis has much to do with the choices a poet makes around substitution of words which suggest the 'other'; they are less logical and prescribed and more intuitive. Cixious asserts that no invention in literature can occur without this sense of otherness, which she links to the unconscious; she is also confident that writing is very much a woman's domain in our era because women find it easier to access this sense of otherness (Cixous \& 
Clément 1986: 84-85). Easthope states that the syntagmatic axis is dependent on the absence of the language which is necessarily omitted. Whilst the syntagmatic chain is more consciously utilised, it is also partly determined by the otherness of the paradigmatic, and the Lacanian unconscious is a function of that Other (Easthope 1983: 37-38). It has also been said that the relationships between words in the paradigmatic axis occur outside the immediate 'neighbourhood' of the text (Pettit 1977: 8). The paradigmatic axis is less visible, then; it makes less 'sense' (or actively disrupts meaning) and may be less consciously used.

Barthes notes the essentially binary nature of discourse in the social sciences (Barthes 1968: 12), and this may be for good reason, if the discernment of binary opposition is a child's 'first logical operation' (Hawkes 1977: 24). Culler notes the usefulness of binarism, since it helps us classify almost anything (Culler 1975: 14-15). But, partly in response to Derrida's critique of logocentrism, Johnson warns that binary oppositions are often organised in gender-inflected hierarchies (Johnson 2004: 343) [1]. Derrida believes there is no natural hierarchy of signs, (Derrida 1997: 44) though some critics have advocated for a hierarchy of paradigmatic relation (Chandler 2007: 94-95). It seems as though healthy use might yet be made of binaries as long as these warnings are kept in mind, along with the acknowledgement that the relational axes are 'mutually dependent' (Easthope 1983: 36). Barthes summarises these two axes as 'two forms of mental activity' (Barthes 1968: 58). Ultimately, if they are two ways of thinking they could be seen as two different ways of writing, an idea to which I will return.

These two ways of thinking are further elucidated by Jakobson's research. He has written extensively on the metonymic use of language (a technique of the syntagmatic chain - Jakobson 2000b: 56). In metonymy, a term is substituted for another where both are linked by subject matter, and are contiguous in relationship, such as 'sail' for 'ship'. His study of aphasia gives clinical evidence for a fundamental difference in the nature of metonymy and metaphor. Aphasics are noted to have problems with either the element of combination or with selection, resulting in contiguity or similarity disorders (Jakobson 1971: 56-67). His evidence supports the idea that the syntagmatic and paradigmatic may represent separate mental capacities, and, subsequently, differing forms of writing [2].

One of many ways in which the relational axes flex or fuse is in the layout of a poem. Poets such as Michele Leggott are aware of spatial relations as tools. For example, Leggott's early poem 'Micromelismata' mimics the shape of lips and forces the poet to consider imaginative ways of using syntax (Leggott 1996). A poet uses a variety of techniques - metonymy, metaphor, euphony, alliteration, etc - to inform and enliven his or her work. Awareness of a corresponding spatial lexicon lends the poet another level of choice. Indeed, the analysis of poetry I have undertaken has led me to ask, 'why so much space?' What are the gaps between words and lines in the layout of a poem and how are they operating? Space may evoke the thought-patterns of the poet, in a kind of mind-map, create a particular rhythm or atmosphere, and assist, rather than break down, certain meaningful connections.

Spatial relations, along with form, are usually regarded as syntagmatic (Chandler 2007: 110). But innovation of form surely comes from that sense of otherness, from departure, or difference; otherwise, why change from an existing, syntagmatic structure, and how is it possible that a new form could evolve from an old form whilst remaining on the same level, or axis? I suggest that the use of space in the examples given is largely paradigmatic rather than syntagmatic, especially as it relates to innovation. One possible reason for the 
lack of spatial experiment even in much contemporary poetry again relates to binary oppositions of space. The polarities up/down and left-right are susceptible to hierarchies. In particular the left/right function tends to be interpreted or labelled as a known/unknown dichotomy, with all its attendant associations of fear (Chandler 2007: 110-112).

Let's now return to Leggott's poem 'Thrills (helpless)'; the second page reads:

or they go breaching the
dawn foet first
hear it?
sing it?
remember?
(helpless you you
The windows
(Leggott 1991: 12)

'Foam feet first,' evokes the sea and perhaps a first walk in it. The spaces between the words 'can you', 'sing it' and 'do you' force one to 'listen' more intensely, if not with the outer ear, then with the inner (sub-vocalisation). The use of 'helpless' with just one bracket is a paradigmatic shift which matches the change of direction in the content. The idea of the windows being open is both a sign of freedom and danger.

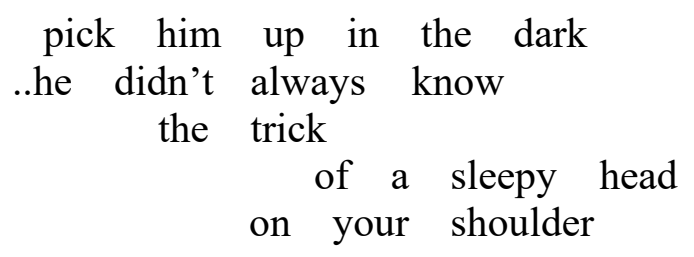

little movie

wide

page

$*$

lign aloes align

paradise shoots

zingiber promise in a lotus pool
ibis kiss this coast
see the sun go round
rages of day decline
swim, moon -

(Leggott 1991: 13-14) 
The poem makes this reader sing. After the child is picked up in the dark, probably following a nightmare suggested by the dangers of the open window, the spaces might imply a gentle singsong tone of voice. I must acknowledge that the link between the visual and aural is uncertain in a poem, just as Drucker notes, in pondering Mallarmé's famous concrete poem 'Il Pleut', the difficulty of deciding at what point the visual produces an aural effect (Drucker 1998: 106). But we cannot afford to overlook the euphony of poetry and its effect on the inner ear. The line 'lign aloes align' is particularly harmonious in its vowel sounds, and the soft letter ens lend comfort. The word 'zingiber' (both a kind of ginger and its Latin name) suggests the erotic, the stuff of children's songs and fantasy. Musicality is maintained by 'ibis kiss,' and 'see the sun go round' is particularly childlike. The rages decline and the child swims in the moon, as it were, gathering itself into a kind of fairy story.

The spaces and pauses are those before sleep; the layout of the poem helps suggest this reading even more fully than the building references to sleeplessness, to a child being comforted and to singing. Spaces seem to be working in conjunction with memories, and embody the situation of the poem by becoming important aspects of its content. Space works paradigmatically here, with content and memory. Inevitably, space has a role to play in the positioning of lines (which is syntagmatic), but it is by no means limited to positioning. I would argue that in this poem, space is itself an act of substitution for language, a key paradigmatic element. This technique attempts to reach across the gap that is formed by what language, as wording, cannot do; we extend our conception of language to include the music that fills spaces in order to 'say' more (or sing more). We interpret gaps by considering how they might be filled, or by giving them meaning as spaces (Culler 1975: 171); in so doing, we give a 'signifying function' to the materiality of the space that makes up the page (Johnson 2004: 346). Drucker likewise asserts that space is 'graphic, specific and produces meaning' (Drucker 1998: 105).

When the form of a poem is unique, such as in 'Thrills (helpless)', one could argue that the use of space in the layout eventually becomes a kind of syntagm, within the duration of the piece, since there is a consistency to its patterning. If space is repeatedly used in the same way, it becomes a form, and there is little doubt that pleasure is gained by visual consistency. But in many cases, Leggott's 'Thrills"' included, this only occurs after it has disrupted reader expectations, conventional language practices and established codes (including spatial ones) and taken us into its own world of artifice. The space in this poem has enabled the reader to arrive at the sense of a lullaby, and it has done so, I would suggest, by disrupting logic, including the way we expect to read lines of a poem on the page; otherness forces change and innovation.

My assertion that space is an act of substitution for language means that space should be considered a function of language. Such spatial variations such as those described may be essential to the fulfilment of the poem's potential to achieve diversity and multiplicity. Just as words are maps for assigning order (Rivkin \& Ryan 2004b: 54), Drucker comments that, 'visual format can mark, prescribe, or record process or the simulation of movement and it can also make use of absent elements as visual presences which participate in the production of meaning;' it is a 'schematic mapping' (Drucker 1998: 103). Similarly, Davidson considers Charles Olson's assertion of the typewriter as a score for the voice and the page as a map or graph (Davidson 1989: 88). Further examples from Leggott's earlier work might shed more light on the issue of the functions of space and layout.

'Tigers' is a series of spherical poems that includes text on the left and right sides of its curves as well as through the centre, which the sides interweave 
(Leggott 1991: 52-54). The effect is at times akin to the double margin field form, originated by New Zealand poet Alistair Paterson (Caffin 1998: 481). This structure controls the reading of the poem, in two margins, and helps separate out differing ideas and threads in the poem [3]. These line variants give visual support to complimentary and related images and ideas, strengthening the sense of mapping. The parallel poems give the overall effect of a group of related pieces, within the one sphere. At times, a second poem acts as a commentary on the first, e.g. 'a / step / into / heaven' which responds to, 'wavejumping/ down the coast/ eight months a year call up' (Leggott 1991: 52). Paradigmatic shifts are sometimes softened by enjambment, for example, 'eight months a year call up / the weather office every morning,' and give the illusion that the syntagm is conventional. The content of this poem, referring as it does to a glass blower and his workshop is especially suited to the spherical structure, which evokes a molten drop. In the other poems from the series, allusions to the rotating of the earth, navigation at sea and tiger eyes give a similar sense of satisfaction of form allied to content.

Each variation of form in 'Tigers', like an artist's series, relies on the poet's imagination to bring it to fruition. Though each is spherical, no two poems are the same in their inner shape, within the spheres. The poems have been structured and confined externally, but freed internally in terms of their supporting structures, so that, again, the use of the otherness of space has forced change and innovation.

Over time, Leggott's poetry has given less emphasis to the visual page-work, though the play of relational axes is no less important. I would now like to consider contrasting facets of a more recent poem.

\section{so far}

on the first day of October in a city without hot water the temperature climbs to 31 degrees and I

in a room with full-length mirrors wash like an odalisque petalled self on the tiled floor, diffuse light as of jalousies or halogen keeping the frescoes chalky

2005: 2)

\section{(Leggott}

Leggott begins with the date, a simple story-telling device. The detail of the city having no hot water might evoke either a type or an exception. The temperature is notable for the poet, suggesting that she is a visitor. Initially, the sequence of syntagms is more or less synonymous with whole lines, and seems logical, with the slight exception perhaps in the comment on hot water. The personification of 'climbs' is almost unrecognisable as such, a fixed syntagm. The poet then uses a slightly old-fashioned form, 'and I', as if Edith Wharton were about to hold forth in Morocco, and a break occurs with this divided fourth line. The room is described with full-length mirrors. The full-length mirrors, which evoke the exotic, seem to suggest 'odalisque' to the poet, by association, extending the exotic code. It is not clear why the phrase 'petalled self' is given in italics; the reader might assume that this is a quotation or reference to a detail of a painting, but the italics themselves have the effect of adding verisimilitude. Both 'petalled self' and the tiled floor are also able to maintain the exotic code. The word 'jalousies' could be read as an archaic spelling if one did not know it as a kind of blind. The word 'halogen' brings us 
to a more modern setting, and disrupts the images that may have been created before it. In some way, the poem might already be said to lack 'thematic unity', in the traditional sense, which helps create the autonomy of the text (Culler 1981: 4). This is also part of the poem's play, and perhaps an example of what Culler quotes Johnson as saying about deconstruction as, 'a careful teasing out of warring forces of signification' (Culler 1981: ix). Eagleton notes Lotman's understanding of a poem as a 'system of systems', whose interactions include 'collisions and disparities', which conflict gives a poem its effects (Eagleton 2007: 52-53), and helps explain this combative aspect of signification. Already, then, a reading which is beyond structuralist may be needed. The frescoes are another detail we associate with earlier historical time frames, but the code has shifted now and use of the colloquial 'chalky' confirms this. The poem tends to exploit misdirection for effect in the manner of the Riffaterrean stage set [4].

2 spruiking
for love's boy on a pavement
covered by fallen blossom
victorious armour
washed away in the night
endless headlights bearing
one avenue to another
three thousand solar showers
have been purchased
since the explosion

2005: 2)
(Leggott

The second, numbered section begins with the word 'spruiking' - more common in Australia than New Zealand - whose origin is unknown, but meaning to advertise in public by speaking. The phrase 'love's boy' seems curiously quaint (perhaps evoking Romeo) and contrasts with the modern 'pavement'. The exotic code both initiated and disturbed in the first stanza seems to be transposing into a romantic code, despite the initial variations of register which 'blossom' and 'victorious armour' give. Line five is rather pragmatic, and line six is again obviously modern. The reference to the number of solar showers also seems pragmatic, and the fact that they were purchased since an explosion explains the earlier reference to the city without hot water. We don't yet know what this explosion was or when it occurred, but, because of the intratextuality, it is syntagmatically coherent, and brings to mind this summary of Jakobson's idea, that, 'syntagmatic relations refer intratextually to other signifiers co-present within the text' (Chandler 2007: 84). As hoped, semiotic terms enhance our appreciation for the techniques of the poet.

To summarise the approach used in this stanza, Leggott's syntagms are either disrupted - from 'love's boy' to the pavement, or generated by association from 'blossom' to 'armour' - or, debatably, move logically - from 'night' to 'headlights', 'avenues' to 'solar showers'. Again, it seems that either the syntagmatic or paradigmatic axes are being exploited so much as to constitute different forms of writing, even the disruption of the syntagm can be seen as a kind of paradigmatic thrust, or, the otherness of the paradigmatic is having an effect. The writing is both descriptive (of the pavement and the night) and symbolic (of love and chivalry) [5]. Again, the competing nature of references seems to indicate a deconstructionist occurrence [6]. It appears that the poem has already leapt beyond the diversity of interpretations that a poststructuralist reading might note, to this sense of opposing ideas and interpretations that might emerge from a text. The poem continues: 
3 the fire-eater juggles
torches knives an iron ball
five teeth missing by the river
his bride sings a cappella
veils tied to a balcony railing
fructus ventris fructus sanctus
white laburnum on the river path
warble on a bike
who will enter the shadows
under the bridge at noon?

2005: 2-3)

\section{(Leggott}

The juggler is undoubtedly juggling by the river, but he is surely not juggling teeth, and the teeth are probably not missing by the river. The enjambment and lack of punctuation disrupts the grammar of the syntagm and the multiplicity frustrates the ordinary sense of meaning. These weird images, though, add colour to the overall evocation.

Continuing the romantic code established earlier, but in contrast to what immediately precedes it (a clear breaking of the order of the syntagm), the text cites the bride. She may be performing with the artist, but we cannot be sure. The word 'veils' continues the romantic code and may even be a metaphorical visualisation of the style of singing that is a cappella, or a literal observation. Pettit suggests that, 'every transgression of a selectional rule constitutes a potential metaphor' (Pettit 1977: 103), and it certainly appears that it is this potential for transgression that the text harnesses, as opposed to distinct and overt examples of specific literary techniques. The Latin which follows may be part of her song, in which case its sequencing from the third line is broken by the fourth, or it is an association with the romantic code, since the first phrase is from the Ave Maria prayer, meaning 'fruit of the womb', and the second means 'sacred fruit'. The reference to white which follows suggests the purity or innocence of anticipation of marriage (romantic code). But next comes 'warble on a bike', a skilful and whimsical metonym. This expression is in a different tone, which may accord with the juggler code. The warble is probably a person whistling, humming or singing on a bicycle, possibly the performer, but it could also be a bird perched on a set of handlebars.

The reference to meeting under the bridge suggests a tryst, embellishing the romantic associations, though a violent tryst is also possible and correlates with the missing teeth reference. The lines elide and leap with joie de vivre and multiplicity. It is possible to identify at least four codes in this stanza: the romantic, the performative, the realistic and the violent. Some phrases are clearly designed to pull one back into the immediacy of what is happening, despite distracting allusions to various phenomena that may or may not be real. Perhaps what emerges is an indication of the tendency in contemporary poetry for the writer to maintain a variety of competing codes, rather than the single code which might have pervaded much poetry of the past [7]. This is stark evidence of the idea that, 'Literature forces one to face the problem of indeterminacy of meaning,' largely because of, 'the undecidable nature of figurative language' (Culler 1981: 35-36).

Niall Lucy reminds us that it is not only semioticians that understand signs in daily life, but that all members of a culture do so (Lucy 2001: 4). Culture, it seems, was a limited subject in ages where the image of God ruled (Lucy 2001 14), just as Derrida's assertion that the era of the sign, with its definitive signified, shares the epoch of divinity (Derrida 1997: 13-15). Lucy suggests 
that semiotics should sit within a much wider structure that critiques difference and oppositions, and that the influence of semiotics has been necessarily supplanted by cultural studies (Lucy 2001: 4, 25). Barthes describes the need to unify research in anthropology, sociology, psychoanalysis and stylistics. The remarkable level of multiplicity of Leggott's poetry would seem to echo Barthes' comment about a 'second-order language' whose unity lies in 'larger fragments of discourse,' and which indicates that semiotics might be absorbed into a kind of translinguistics, possibly including, 'even the inner language which is ruled by imagination' (Barthes 1968: 11). These references to multiplicity and cultural studies bring to mind assemblage theory as the holistic framework within which semiotics might come to dwell. Even a conventional structuralist understanding may see literature as an 'assemblage of signs', as Rivkin and Ryan write in discussing Barthes (Rivkin \& Ryan 2004b: 54). But assemblage is more than the sign. Little quotes Bryant that though assemblages may be fully comprised of bodies, 'there are no assemblages composed entirely of signs and utterances' (Little 2012). Whilst this idea reminds us of the Saussurean understanding of the sign as contextualised like the language user, it takes context much further [8]. Assemblage accommodates the poem as the 'system of systems' (mentioned above) and the, at times, awkwardness of opposing significations that deconstruction highlights.

Assemblage theory seems to resist definition, however, and tends to describe itself in context upon context; diversity being paramount. The following description is illustrative of such diversity, and concerns this paper very much as it may be seen as reflecting vividly on Leggott's poetry: 'There are only multiplicities of multiplicities forming a single assemblage, operating in the same assemblage: packs in masses and masses in packs' (Deleuze \& Guatarri 1988: 34). We seem only to be able to describe a variety of threads through 'so far' and 'Tigers', rather than arriving at any idea of thematic unity, or even of a kind of single culmination of effects, as in 'Thrills'.

Interestingly, Deleuze and Guatarri's discussion agrees with Austin's thesis of speech and action, which calls into question the very idea of a code - used frequently in this discussion - 'since a code is the condition of possibility for all explanation' (Deleuze \& Guatarri 1988: 77). This seems to suggest a kind of radical relativism, which nonetheless embraces, rather than pushing away, the indeterminacy of the poetry and its attendant sense of otherness.

Let us continue with 'so far' a little longer to see where such indeterminate language might take us:

4 the tests were successful
and service may be resumed
sooner than expected
I live like Utnapishtim in the distance
six floors up in a confluence
where Brunton meets Jolimont
that is how we got here
the trains wake me before dawn
each day is a bird in another place

2005: 3)

The comment on tests and services being resumed in the fourth stanza again connects with the idea of the explosion, and the juxtaposition with the ending of the third stanza's romantic allusion jolts the reader back to the present. Also, 
'the tests' could now mean something else, as if the romantic had to be tested for soundness, so that a kind of comparison between codes occurs, as well as the breaking off from one to another. The poet next likens herself to Utnapishtim, a character in the Epic of Gilgamesh, who serves a role similar to that of Noah in the Biblical flood story. The way she is living might well be something the reader would expect her to comment on in the midst of privations, but to identify with such an ancient story is a surprise. Reference to the sixth storey is also a minor shock given the code being created, and the use of 'confluence' which we associate with rivers and which would otherwise accord so well with the Gilgamesh theme, becomes another unexpected twist. The text returns to the names of streets, which add further, plausible detail. The seventh line is a flashback, a thought tangent, showing that the poet expects to be able to utilise the idiosyncrasies of the mind, or, in linguistic terms, her idiolect [9]. The trains make an early alarm call, but the voice seems to relish the opportunity to encounter the newness of things, and the ninth line is again one which breaks the syntagmatic flow established by the previous. She is awake in time for the dawn chorus, and each day being, 'a bird in another place,' works multi-dimensionally. It could be a pleasing metaphor and an example of what is seen: those with an interest in the subject look out for new birds in new places. Alternatively, it may be a metonymic choice. But, though the poem seemed earlier to evoke a European city, the names Brunton and Jolimont together (along with the reference to the Shrine of Remembrance in the next section) now indicate Melbourne [10]. We are not in some exotic, European or Eastern city, but in Australia - not such a distant reality for a New Zealand poet. Riffaterre argues that any sign within a text is present for its potential poetic quality, and, from a specific example, also shows that a single word which brings unity to the poem could in fact be absent from it (Riffaterre 1978: 3); in this case, exotic allusions abound, but the name, Melbourne, evades us. This omission also evokes Derrida's concept of the centre of a text being outside the text itself (Derrida 2001: 351-353) and is an extreme of the sense of otherness in poetry [11].

To summarise, both syntagmatic and paradigmatic axes are used with aplomb in 'so far'. The paradigmatic juxtapositions build on each other, seeming to create coherent, yet unstable, wholes. Leggott achieves multiplicity with a profusion of codes. Examples of Riffaterre's definition of semiotics as the transferral of a sign from one level of discourse to another (Riffaterre 1978: 4) are plentiful here. They are found, not surprisingly, where the most unexpected things occur, when a code is established and swiftly broken, when the syntagm is disrupted or when juxtapositions of lines or stanzas suggest new readings.

In contrast with 'Tigers', I would argue that in 'so far', the syntagmatic line has been liberated to more frequent paradigmatic surprises, which give, in some ways, a similar effect, at least in terms of originality. Originality of form is immediately visible in 'Tigers'. Whereas, in 'so far', the conventionality of line stanza and line breaks is gradually teased out of stability. Both series include powerful paradigmatic changes. Furthermore, I would suggest that the manipulation of layout in 'Tigers' cannot be regarded as syntagmatic because sequentiality of the syntagm is broken, as is logic. Logic sets out thoughts one at a time, in the same way that the syntagm only occurs singly (Barthes 1968: 58). At least two significant characteristics of the syntagm are exceeded here: sequentiality and singularity.

The musicality of 'so far' is no less pronounced than that of 'Thrills (helpless)' though exhibiting different qualities. And, if anything, Leggott's work exemplifies multiplicity more than ever before, with its diverse and vacillating codes. In general, space can undoubtedly aid the sense of movement in a poem (see Drucker, above), and as suggested, contribute directly to its content, 
analogous to the use of silence in music. Apart from the break across lines three and four, there are no striking uses of space in the layout of this portion of 'so far' and very few in the rest of the poem's twelve pages. Rather, the poem has an extremely compressed quality and the lack of space in the layout helps conflate ideas in intriguing and suggestive ways. One could say that the gaps of meaning and numerous contexts are closed down in the poem (or filled up as Culler might say), to be brought together in a welter of possibilities. It would seem as though the use of space is but one tool in the poet's range and its use is determined by the needs of each poem, as well as the poet's own situation, time and place. In the cases outlined, space creates meaning and affects in the same way language does. The times and places of each poem discussed are inclined to fight convention, seeking perhaps a more complete understanding of the multiplicity of ourselves, as well as language. Awareness of the use of syntagmatic and paradigmatic relations in poetry, including the function of space within those axes, may mean that the poet can utilise these functions more consciously and by so doing enhance and manipulate effects. With this awareness comes the realisation that the way space is used on the page is potentially as strong a force as any that the poet possesses.

\section{Notes}

[1] This view of binary oppositions is also implicit in Cixous' writing (Cixous \& Clément 1986: 63-72). return to text

[2] Jakobson's focus on metonymy is partly in reaction to what he sees as an over-emphasis on metaphor by critics and linguists. This is perhaps because it is one of the most consistent and easily identified paradigmatic techniques. He is so conscious of this inclination that he speculates, somewhat whimsically, that the discourse itself may have a contiguity disorder (Jakobson 2000b: 59). return to text

[3] Leggott also includes a variant of the double margin in this collection, and for short periods creates as many as three parallel poems which can be read separately or as through pieces Parallel poems occur occasionally in Milk \& honey (2005), but with much less complexity, the second grouping tending to function as notes ('faith and rage', 14-23; though there is an interesting double margin type effect in 'words beyond light', 48). return to text

[4] Riffaterre describes one example of poetic misdirection as causing the reader to be sent to a landscape which seems real but is, 'a stage set for special effects' (Riffaterre 1978: 6-7). return to text

[5] Description is associated with consonance and symbol with dissonance, 'rationalized as imagination' (Riffaterre 1973: 229). return to text

[6] I use the word 'occurrence' conscious of Derrida's warning that deconstruction is not a method but something that arises from reading certain texts. return to text

[7] Riffaterre's discussion of Wordsworth's 'Yew-Trees' describes a kernel word used to establish a code, which is then embellished by other related terms; the codes change but gradually (Riffaterre 1973: 235-249). return to text

[8] The one area where assemblage does not fit well with this discussion is in that of the understanding of the sign. Opposed to the Saussrean sign, Deleuze and Guatarri's semiotics is a fusion of Peirce's and Hjelmslev's triads, where content is not a signified and expression is not a signifier, but both are variables of an assemblage (Semetsky 2005: 242). return to text

[9] Barthes discusses this concept from Martinet as the speech of a single individual. Though Jakobson questioned its validity, since language is always socialised, Barthes himself offers examples of the aphasic, the analogous issue of the style of an individual writer, and the character of language of a linguistic community in support of the idea. He claims that attempts to make use of the idiolect show a desire for an intermediary between speech and language, paralleling a similar need with regard to signified and signifier that Hjelmslev identified with his 'schema/ norm/ usage' theory of the sign (Barthes 1968: 17-18); Peirce's 'interpretant/ 
representamen/object' allows for materiality outside the sign system (Chandler 2007: 33). return to text

[10] It is as if the reader has been tricked, and Riffaterre's idea of 'a stage set for special effects' again comes to mind. return to text

[11] Derrida believes that structure has classically been regarded as having a centre which helped limit the play of the structure. The centre closes off a degree of substitution which cannot occur at the centre itself, so governing the structure but also escaping it, confirming itself within and outside the structure at the same time; the centre does not belong to the totality, and so has its centre outside; 'the centre is not the centre' (Derrida 2001: 352). It is a baffling concept, but one which highlights some limitations of the sign as a principle tool for the analysis of texts. Riffaterre's and Derrida's theories are surprisingly compatible for the way that each allows for the play of a poem, and the way that it releases the reader from concerns about, 'what language does to reality,' because he or she has to leap that hurdle to read the poem's message (Riffaterre 1978: 6). return to text

\section{Works Cited}

Barthes, R 1968 Elements of semiology, Hill \& Wang, New York return to text

Caffin, E 1998 'Poetry, part two: 1945-1990s', The Oxford History of New Zealand Literature in English, ed T Sturm, 2nd edn., Oxford University Press, Auckland return to text

Chandler, D 2007 Semiotics - the basics, Routledge, London return to text

Cixous, H \& C Clément 1986 The newly born woman, trans B Wing, University of Minnesota Press, Minneapolis return to text

Culler, J 1975 Structuralist Poetics - Structuralism, Linguistics and the Study of Literature, Routledge \& Kegan Paul, London return to text

Culler, J 1981 The pursuit of signs - semiotics, literature, deconstruction, Routledge \& Kegan Paul, London return to text

Davidson, M 1989 'Palimtexts: postmodern poetry and the material text', in M Perloff (ed) Postmodern Genres, University of Oklahoma Press, Norman: 75-95 return to text

Deleuze, G \& F Guatarri 1988 A thousand plateaus - capitalism and schizophrenia, trans B Massumi, Continuum, London return to text

Derrida, J 1997 Of grammatology, trans GC Spivak, John Hopkins University, Baltimore MD return to text

Derrida, J 2001 Writing and difference, Routledge, London return to text

Drucker, J 1998 Figuring the word - essays on books, writing and visual poetics, Granary, New York return to text

Eagleton, T 2007 How to read a poem, Blackwell, London return to text

Easthope, A 1983 Poetry as discourse, Methuen, London return to text

Hawkes, T 1977 Structuralism and semiotics, Methuen, London return to text

Jakobson, R 1971 Studies on child language and aphasia, Mouton, Paris return to text

Jakobson, R 2000a 'Linguistics and poetics' in D Lodge (ed) Modern criticism and theory - a reader, Pearson, Harlow: 31-55 return to text

Jakobson, R 2000b 'The metaphoric and metonymic poles' in D Lodge (ed) Modern criticism and theory - a reader, Pearson, Harlow: 56-60 return to text

Johnson, B 2004 'Writing', in J Rivkin \& M Ryan (eds) Literary theory: an anthology, Blackwell, Oxford: $340-347$ return to text 
Kristeva, J 1984 Revolution in poetic language, Columbia University Press, New York return to text

Leggott, M 1991 Swimmers, dancers, Auckland University Press, Auckland return to text

Leggott, M 1996 Dia, Auckland University Press, Auckland return to text

Leggott, M 2005 Milk \& honey, Auckland University Press, Auckland return to text

Little, D 2012 'Assemblage theory’, Understanding Society:

http://understandingsociety.blogspot.com.au/2012/11/assemblage-theory.html (accessed $03 / 06 / 15$ ) return to text

Lucy, N 2001 Beyond semiotics - Text, Culture and Technology, Continuum, London return to text

Martin, B \& F Ringham 2006 Key terms in semiotics, Continuum, London return to text

Pettit, P 1977 The concept of structuralism: a critical analysis, University of California Press, Berkeley return to text

Riffaterre, M 1973 'A reading of Wordsworth's "Yew-Trees", New Literary History 4, 20: 229-256 return to text

Riffaterre, M 1978, Semiotics of poetry, Indiana University Press, Bloomington return to text

Rivkin, J \& M Ryan 2004 'Introduction: formalisms', in J Rivkin \& M Ryan (eds) Literary theory: an anthology, Blackwell, Oxford: 3-6 return to text

Rivkin, J \& M Ryan 2004b 'Introduction: the implied order: structuralism' in J Rivkin \& M Ryan (eds) Literary theory: an anthology, Blackwell, Oxford: 53-55 return to text

Saussure, F de 2005, Course in general linguistics, eds C Bally \& A Sechehaye, collab A Riedlinger, trans R Harris, Duckworth, London return to text

Semetsky, I 2005 'Semiotics', The Deleuze dictionary, ed A Parr, Columbia University Press, New York: 242-244 return to text

Owen Bullock is a PhD Candidate in Creative Writing at the University of Canberra. His publications include urban haiku (Recent Work Press 2015), tracer (Ampersand Duck 2015), breakfast with epiphanies (Oceanbooks, NZ 2012) and sometimes the sky isn't big enough (Steele Roberts, NZ 2010). He is a former editor of Poetry New Zealandand Kokako; edited anthologies for the New Zealand Poetry Society; was one of the editors who produced Take Five: Best Contemporary Tanka, Vol IV, and Underneath - The University of Canberra's Vice-Chancellor's International Poetry Prize 2015 (with Niloofar Fanaiyan).

\section{TEXT}

Vol 19 No 2 October 2015

http://www.textjournal.com.au

General Editor: Nigel Krauth. Editors: Kevin Brophy \& Enza Gandolfo text@textjournal.com.au 